\title{
Advanced hemostasis in axillary lymph node dissection for locally advanced breast cancer: new technology devices compared in the prevention of seroma formation
}

Claudio Gambardella ${ }^{1 *}$ (D) Guglielmo Clarizia ${ }^{1}$, Renato Patrone ${ }^{1}$, Chiara Offi ${ }^{1}$, Claudio Mauriello ${ }^{1}$, Roberto Romano ${ }^{1}$, Marco Filardo ${ }^{1}$, Alessandra Conzo ${ }^{1}$, Alessandro Sanguinetti ${ }^{2}$, Andrea Polistena ${ }^{2}$, Nicola Avenia ${ }^{2}$

and Giovanni Conzo'

\begin{abstract}
Background: Breast cancer is the most frequent neoplasm in women. Axillary lymph nodes dissection represents the treatment of choice in locally advanced breast cancer for prognostic and curative purposes. Seroma formation, an abnormal collection of fluid in the dead space of the axilla, is described in Literature with a wide range of incidence (3-85\%). It is a source of significant morbidity and discomfort. The aim of the study is to compare the different haemostasis devices used in breast surgery, investigating the eventual superiority of an instrument among the others in terms of intraoperative and postoperative outcome, especially of seroma formation.

Methods: Clinical cases of female patients undergone axillary lymph nodes dissection for local advanced breast cancer between January 2013 and July 2017 at the Surgery Unit of University of Campania "Luigi Vanvitelli" were retrospectively reviewed. Patients were divided into four groups, according to device utilized during surgery: Electrocautery, Harmonic Scalpel, LigaSure and Thunderbeat. All patients underwent II level axillary lymph nodes dissection associated to radical mastectomy or quadrantectomy.

Results: One hundred consecutives patients were enrolled in the study. Intra-operative blood loss resulted statistically significant different $(P<0,01)$ between the Electrocautery group $(94,7 \mathrm{ml})$ and the Thunderbeat group $(57,2 \mathrm{ml})$, while the Harmonic Scalpel group and the Ligasure group, despite presented a lower amount of blood loss, did not differ significantly. Drainage volume resulted significantly lower $(P=0,002)$ in the comparison between the Electrocautery group and the Thunderbeat group; the Ligasure group and Harmonic Scapel group showed no difference between them and Electrocautery group. About the seroma formation, the Electrocautery group resulted affected by the highest seroma formation rate (64\%). Seroma incidence in Harmonic Scalpel group was 24\%, in Ligasure group was 44\%, while Thunderbeat group showed the lowest presentation of seroma with $16 \%$.

Conclusions: In patients affected by breast cancer requiring axillary lymphnodes dissection, the use of advanced hemostasis devices is highly desirable. Among the non-traditional tools, Thunderbeat resulted to be superior in terms of reduction of intra-operative blood loss and post-operative drainage output, moreover associated to a substantial reduction of postoperative seroma incidence.
\end{abstract}

Keywords: Advanced breast cancer, Axillary lymphnodes dissection, Advanced hemostasis device, Seroma

\footnotetext{
* Correspondence: claudiog86@hotmail.it

${ }^{1}$ Division of General and Oncologic Surgery - Department of Traslational

Medical Sciences, University of Campania "Luigi Vanvitelli", Via Sergio Pansini

5, 80131 Naples, Italy

Full list of author information is available at the end of the article
}

(c) The Author(s). 2019 Open Access This article is distributed under the terms of the Creative Commons Attribution 4.0 International License (http://creativecommons.org/licenses/by/4.0/), which permits unrestricted use, distribution, and

reproduction in any medium, provided you give appropriate credit to the original author(s) and the source, provide a link to the Creative Commons license, and indicate if changes were made. The Creative Commons Public Domain Dedication waiver (http://creativecommons.org/publicdomain/zero/1.0/) applies to the data made available in this article, unless otherwise stated. 


\section{Background}

Breast cancer is the most frequent neoplasm in women, with an incidence of fifty thousand new cases diagnosed in Italy in 2017 [1].

Oncological treatment for breast cancer experienced substantial modifications in the past decades, tending to a less invasive approach. The introduction of new screening programs permits to diagnose breast cancer in earlier stages [2, 3], allowing a conservative surgery for tumor stages I-II, associated to sentinel lymph-node biopsy (SLNB), in case of clinically and imaging negativity of Axillary Lymph Nodes (ALN) [2, 4]. Nevertheless, axillary lymph node dissection (ALND) is still considered the gold standard approach in association with radical mastectomy (RM) either quadrantectomy $(\mathrm{Qu})$, for the treatment of locally advanced breast cancer with positive lymph nodes, determined by fine needle cytology (FNC) or a core-needle biopsy, or in selected cases of stage IV tumors [1].

Recent guidelines from the US National Comprehensive Cancer Network describe locally advanced breast cancer as the American Joint Committee on Cancer stage III breast cancer. The definition includes breast cancer that fulfils any of the following criteria in the absence of distant metastasis:

- Tumours more than $5 \mathrm{~cm}$ in size with regional lymphadenopathy (N1-3)

- Tumours of any size with direct extension to the chest wall or skin, or both (including ulcer or satellite nodules), regardless of regional lymphadenopathy

- Presence of regional lymphadenopathy (clinically fixed or matted axillary lymph nodes, or any of infraclavicular, supraclavicular, or internal mammary lymphadenopathy) regardless of tumour stage [4].

ALND is associated to different postoperative complications, such as lymphorrhea, seroma formation, lymphedema and functional limitation of the shoulder and of the upper limb. In particular, post-operative seroma formation, a collection of fluid in the dead space of the axilla, is described in Literature with an extremely wide range of incidence, from 3 to $85 \%[5,6]$.

Despite many surgeons consider seroma as a mere post-operative side effect, this complication leads to prolonged hospital stay, discomfort and delayed wound healing. Therefore, seroma formation may implicate delayed beginning of adjuvant therapy, affecting oncological outcomes $[7,8]$.

Risk factors and physiopathology of post-operative seroma are still matter of debate, but the main hypotheses are the cellular damage by thermal effect, and the incomplete vessels and lymph ducts obliteration during the dissection $[9,10]$.
Many procedures have been proposed in order to reduce the seroma formation (physiotherapy, external compression and use of pharmacological aids such as hemostatic biological adhesives), but none of them produced effective and definitive results $[11,12]$.

Drain placement is nowadays the only valid method to reduce and treat seroma formation, but on the other hand it leads to discomfort, pain, functional limitation of the arm and its prolonged maintenance may be a cause of infection [12].

The utilization of new devices, widely used in laparoscopic surgery, providing a lower cellular damage and a better vessel sealing and hemostasis, could reduce seroma formation and improve post-operative healing, allowing an earlier beginning of adjuvant therapy. Electrocautery (EC) is an efficient device for ALND surgery, due to an easy manageability and a successful hemostasis, but the high emanated heat strongly affects the incidence of seroma [13].

Introduced in 1990, the Harmonic Scalpel ${ }^{\mathrm{TM}}$ (HS) (Ethicon, Somerville, NJ) is a system that allows cutting and hemostasis without the application of electrical energy to the patient. It is based on mechanical energy at a high frequency of $55.5 \mathrm{kHz}$ and it have long been proven to decrease complications and operative time in both open and laparoscopic surgery. Mechanical energy, transmitted by an active blade, results in collagen molecules within the tissue denaturation, generating coagulum with lower thermal injury $\left(<150^{\circ} \mathrm{C}\right)$ compared to EC. The direct application of ultrasound produces surgical dissection and hemostatic effect, with obliteration of vessels up to $6 \mathrm{~mm}$ in diameter [14-16].

LigaSure $^{\mathrm{TM}}$ (LS) (Covidien, CO, USA) is an electro-thermal bipolar vessel-sealing system, providing hemostasis by a combination of pressure and electro-thermal energy. This device allows cutting as well as ligation of blood vessels up to $7 \mathrm{~mm}$ in diameter, and its application is described in Literature for thyroidal, urological, gynecological and colorectal procedures [17].

Thunderbeat $^{\mathrm{Tm}}$ (TS) system (Olympus Medical Systems Corp., Tokyo, Japan) is a multifunctional device, which integrates both ultrasonic and advanced bipolar energy in a single instrument, taking advantage of both kinds of energy, and realizing rapid tissue cutting and reliable vessel sealing [18].

The aim of the current study is to compare the different haemostasis devices used in breast surgery, investigating the eventual superiority of an instrument among the others in terms of intraoperative and postoperative outcome, especially of seroma formation.

\section{Methods}

Study design

Clinical cases of female patients undergone ALND for breast cancer between January 2013 and July 2017 at the 
General and Oncological Surgery Unit of University of Campania "Luigi Vanvitelli" (Naples - Italy), were retrospectively reviewed. The diagnosis was reached via fine needle cytology (FNC) or core biopsy. All patients had pathologically confirmed ALN metastases. Preoperative written consent was obtained from all participants. Patients with distant metastases, patients underwent neoadjuvant chemo-radiotherapy, patients presenting, at the time of surgery, blood clotting or immune system alterations, patients receiving anticoagulant treatment, and patients undergone previous surgeries on axilla or breast surgeries, were not included in the study. Patients were divided into four groups, according to device utilized during surgery: Electrocautery (EC), Harmonic Scalpel (HS), LigaSure (LS) and Thunderbeat (TB). The Authors included the first 25 subsequent procedures of each group in chronological order, in order to obtain comparable data. Pre-operative, intra-operative and post-operative data of every group were collected from patients' medical records.

\section{Management}

Before surgery, all patients received antibiotic prophylaxis. All patients underwent II level ALND, with extension to III level in case of macroscopic metastatic presence at II level [1], associated to RM or Qu. All procedures were performed by the same equip experienced in breast surgery according to standardized surgical technique described in Table 1 . At the end of every procedure, a closed suction Redon drain was placed in the axilla cavity. In case of mastectomy, a single close-suction drain with a long tip was used to drain both breast cavity and axilla. After surgery, drain output was recorded daily and the drain was removed when the output was less than $30 \mathrm{ml} /$ day. Possible complications were recorded daily in the medical records as well. Seroma collection was clinically recognized, measured and drained by ultrasound (US) guidance, and the amount of serum was recorded. At the discharge, patients' follow up consisted of clinical evaluation at the day 7-15-30, and eventual complications were also recorded.

\section{Statistical analysis}

Continuous variables were described as median (age, drainage volume) or mean (Intraoperative times, intraoperative blood loss, drainage removal) and range, while categorical variables were described as number of cases and percentage. Intraoperative blood loss and drain volume were analyzed with normality test of Kolmogorov-Smirnov. Paired t-test was performed to compare the variable intraoperative blood loss, while we performed Test of Proportions for the variable "seroma". Moreover, the Authors performed the non-parametric 2 independent samples, Kolmogorov-Smirnov test to analyze the statistical difference of the drain volume. Statistical significance was considered in case of $P$ value $<0,05$. Statistical analysis was performed with SPSS version 23 (SPSS $\odot$, Chicago, IL, USA).

\section{Results}

From January 2013 to July 2017, 100 consecutives female patients were enrolled in the current study. Patients were retrospectively assigned to one of the four groups according to the device used during surgery. Demographic data about every group are reported in Table 2 . Regarding surgery, intra-operative time was lower in the EC group (137,5 min for a TM + ALND, 88 min for a Qu + ALND) than in all the other groups. (Table 3) Comparing data about intra-operative blood loss for the ALND surgical time, it resulted a statistically significant difference $(P<$ $0,01)$ between the EC group $(94,7 \mathrm{ml})$ and the TB group $(57,2 \mathrm{ml})$. (Fig. 1) The HS group and the LS group, despite presented a lower amount of blood loss, did not differ significantly compared to EC. (Table 3 ) The number of harvested lymph nodes instead was similar for all four groups. Concerning post-operative output, drainage volume resulted significantly lower $(P=0,002)$ in the comparison between the EC group and the TB group. (Table 4) Regarding post-operative complications, the EC

Table 1 Surgical technique

\begin{tabular}{ll}
\hline Surgical Technique & Description \\
\hline Radical Mastectomy (RM) & $\begin{array}{l}\text { Elipsoid incision including the skin portion to be removed. Preparation of the posterior and the anterior } \\
\text { strip of skin, followed by breast gland removal in toto, including the neoplasm, with the respect of } \\
\text { pectoral fascia. }\end{array}$ \\
Quadrantectomy (Qu) & $\begin{array}{l}\text { Diamond shape incision, including the tumor cutaneus projection in the middle. Removal of the breast } \\
\text { gland until the fascial plan of the underlying muscle. The lateral thickness of removed healthy gland } \\
\text { must be at least } 1 \mathrm{~cm} \text { from the neoplasm }\end{array}$ \\
Axillary Lymph Node Dissection (ALND) & $\begin{array}{l}\text { Incision up the skin projection of the large dorsal muscle (extension of the ellipsoid excision when } \\
\text { associated to RM, separate excision when associated to Qu). Preparation of the posterior and anterior } \\
\text { strip of the skin, lax tissue removal until the axillary vein, section of intercostobrachial nerve. Identification } \\
\text { of the dorsal bundle (arthery, vein, nerve) and the thoracic nerve (N. of Bell) that must be preserved } \\
\text { (I level). Expostion and section of the pectoralis minor, in order to access the underlying lymphonodes } \\
\text { (II level). Identification of the subclavian tendon and subclavian vein, exciding the lax tissue until the } \\
\text { medial edge of the pectoralis minor previously sectioned (III level) }\end{array}$ \\
\hline
\end{tabular}


Table 2 Demographic data, tumor location, patients' comorbidities - EC (Elettrocautery); HS (Harmonic Scalpel); SM (LigaSure); TB (ThunderBeat); UEQ (Upper-External Quarter); UIQ (Upper-Internal Quarter); LEQ (Lower-External Quarter); LIQ (Lower-Internal Quarter)

\begin{tabular}{|c|c|c|c|c|}
\hline & EC & $\mathrm{HS}$ & LS & TB \\
\hline Patients, $n$. & 25 & 25 & 25 & 25 \\
\hline Age - median [range], yrs & $52[33-70]$ & 49 [35-73] & $45[27-61]$ & $54[37-68]$ \\
\hline Laterality - right breast, n. (\%) & $15(61 \%)$ & $18(72 \%)$ & $11(44 \%)$ & $14(56 \%)$ \\
\hline Tumor location - UEQ, n. (\%) & $13(52 \%)$ & $14(56 \%)$ & $15(60 \%)$ & $11(44 \%)$ \\
\hline Tumor location - UIQ, n. (\%) & $6(24 \%)$ & $5(20 \%)$ & $6(24 \%)$ & $7(28 \%)$ \\
\hline Tumor location - LEQ, n. (\%) & $4(16 \%)$ & $4(16 \%)$ & $4(16 \%)$ & $3(12 \%)$ \\
\hline Tumor location - LIQ, n. (\%) & $2(8 \%)$ & $2(8 \%)$ & $0(0 \%)$ & $4(16 \%)$ \\
\hline Body mass index - median [range], $\mathrm{Kg} / \mathrm{m} 2$ & $27,1[19-35]$ & $26[20,5-34]$ & $24,5[18,6-30,2]$ & $26,8[22-31,5]$ \\
\hline Comorbidities - hypertension, n. (\%) & $5(20 \%)$ & $6(24 \%)$ & $4(16 \%)$ & $5(20 \%)$ \\
\hline Comorbidities - Diabetes, n. (\%) & $1(4 \%)$ & $1(4 \%)$ & $1(4 \%)$ & $0(0 \%)$ \\
\hline
\end{tabular}

group resulted affected by the highest seroma formation rate (64\%), while its incidence in HS group was $24 \%$ of the cases, in LS group was $44 \%$ of the cases, and TB group showed the lowest presentation of seroma with $16 \%$ of the treated patients. (Table 4, Fig. 2) Specifically, the TB group resulted significantly different with EC group $(p=0,004)$ and LS group $(p=0,035)$. In the present series, TB application resulted also in a lowest rate of lymphedema presentation. (Table 4).

\section{Discussion}

Radical breast surgery and ALND indications experienced a substantial reduction for the widespread of conservative surgery associated to SLNB [4, 19-21], which contributed to an effective and less invasive treatment of early-stage breast cancers $[4,22,23]$. Nevertheless, radical or conservative breast surgery, associated to ALND and followed by adjuvant therapy remains the main approach for treating advanced-stage breast cancer with pathologically confirmed lymph node involvement.

Seroma formation is considered by many Authors as a simple post-operative side-effect [9], but on the other hand, several researches underlined how seroma formation leads to a delay in wound healing, implying a delay in adjuvant therapy beginning $[24,25]$. Thus, it is clear the paramount importance of preventing post-operative seroma formation, that could be considered the most frequent complication after breast cancer surgery.

Unfortunately, nowadays definitive etiology and physiopathology of seroma formation are still unknown, despite different hypothesis were expressed, such as acute inflammatory reaction following surgical trauma, response to increased fibrinolytic activity in serum and lymph, reduction of fibrinogen levels in plasma $[9,10,26-28]$. Therefore is extremely hard to achieve an evidence-based therapy.

Patient's high body mass index, hypertension, preoperative radiation, tumor size, extended breast surgery, extended axillary lymph node involvement and the use of electrocautery have all been related to seroma formation [29-36].

Various attempts have been proposed in order to reduce seroma formation, such as external compression dressing [37], drainage placement [38-41], usage of fibrin glue [42, 43], flap fixation and obliteration of the dead space [44], unfortunately with inconsistent results.

Several Authors proposed that post-operative seroma is due to an unsuccessful closure of lymphatic and arterial vessels of the breast and the axilla, in association to thermal damage [45, 46]. Considering these hypotheses, the application of EC in association with vessels sealing by laces (standard technique) $[47,48]$, would be the principle cause of seroma formation, whereas the smallest vessels would not be bound, and the EC's overheating would

Table 3 Type of surgery and intra-operative data - EC (Elettrocautery); HS (Harmonic Scalpel); SM (LigaSure); TB (Thunder Beat); RM (Radical Mastectomy); Qu (Quadrantectomy)

\begin{tabular}{lllll}
\hline & EC & HS & LS & TB \\
\hline Radical Mastectomy + ALND - n. (\%) & $8(32 \%)$ & $11(44 \%)$ & $9(36 \%)$ & $9(36 \%)$ \\
Quadrantectomy + ALND - n. (\%) & $17(68 \%)$ & $14(56 \%)$ & $16(64 \%)$ & $16(64 \%)$ \\
Intraoperative time (RM + ALND) - mean [range], min. & $137,5[100-170]$ & $159,5[140-190]$ & $150,3[118-220]$ & $147,8[10-205]$ \\
Intraoperative time (Qu + ALND) - mean [range], min. & $88[60-100]$ & $90,3[55-110]$ & $91[50-108]$ & $99,4[60-135]$ \\
Intra-operative blood loss - mean [range], mL & $94,7[32-150]$ & $76,5[30-129]$ & $81,6[23-135]$ & $57,2[22-103]$ \\
Lymph nodes harvested - mean [range], $n$. & $14,9[7-26]$ & $15,4[6-28]$ & $15[8-28]$ & $14,3[6-26]$ \\
\hline
\end{tabular}




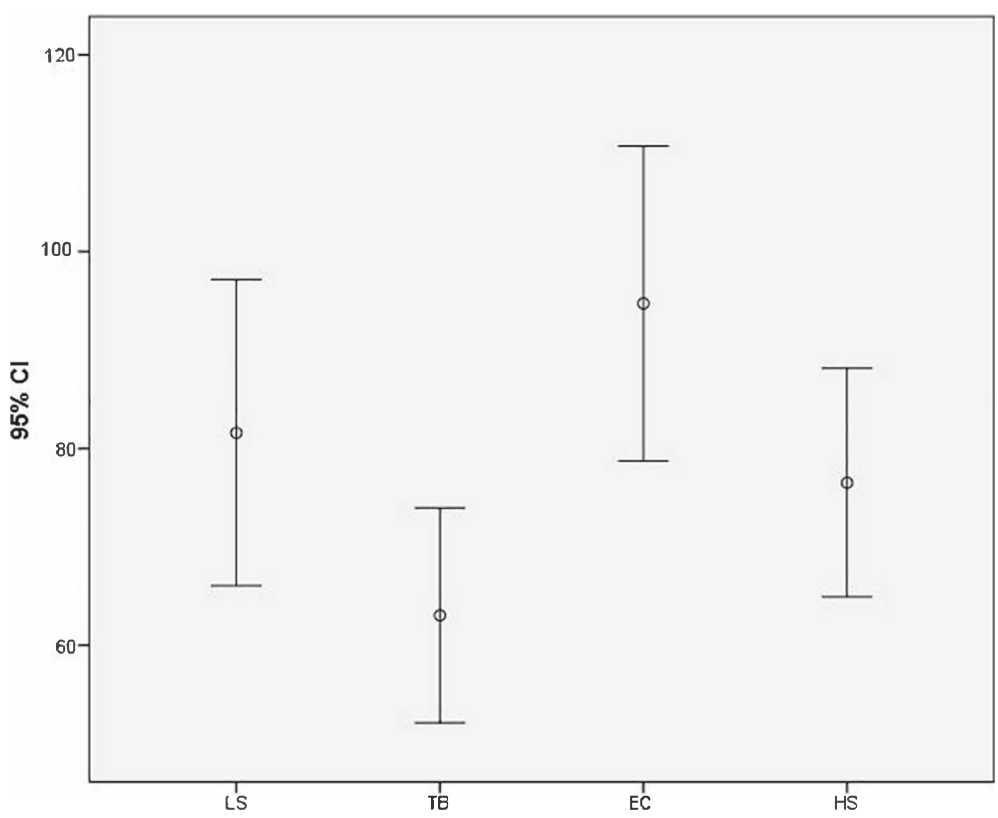

Fig. 1 Error bar for graphical representations of the variability of data. Each Error Bar of Intraoperative Blood Loss is constructed using $95 \% \mathrm{Cl}$ of the means

generate thermal cellular damage [49]. For this reason, different Authors started proposing the use of alternative devices, in order to obtain a better binding and a reduced thermal damage. It is worldwide accepted that the use of advanced hemostasis devices reduces the use of clips and clamps and ties maneuvers, with lower thermal trauma compared to EC. They are easy, manageable instruments, needing a short learning curve [16].

HS, based on ultrasound energy technology, was proposed as an alternative device in the ALND. About its application, opposing results are present in Literature: a meta-analysis from 2012 by Currie et al. [50] implied that no difference was present between HS and EC as regard to intra-operative time, blood loss, drainage volume and seroma formation. Conversely, subsequent studies, reported significant reduction in seroma formation [51-53], reduced intra-operative time [54], reduced intra-operative blood loss [55] and reduction in drainage output [56]. On the other hand, Militello et al. [14], Selvendran et al. [57] and Manjunath et al. [58] showed how the application of HS did not reduce the incidence of seroma after breast surgery. Furthermore, despite the alternative results, various studies underline the high costs for the usage of HS $[52,57,58]$.

Other Authors proposed LS to be the superior device in breast surgery and ALND, but also in these cases, the results are not conclusive. In fact, even if pro studies underlined how the LS utilization led to reduced intraoperative time [59-61], reduction of drainage output $[60,62]$, conversely, several Authors showed no substantial difference when compared to EC [63-66], underlining also a not significant reduction of the cost of hospitalization [67].

No studies in Literature proposed the utilization of TB for breast surgery, which is nowadays frequently described in thyroid and laparoscopic surgeries, showing proficient results $[16,67]$. TB is the last synthesis device introduced in surgery which exploit the combination of high-frequency bipolar energy and ultrasound energy. This synergy allows the synthesis and cutting of vessels up to $7 \mathrm{~mm}$ in diameter with minimum radial heat dispersion and a short time of application. Specifically, the

Table 4 Post-operative data and complications - EC (Elettrocautery); HS (Harmonic Scalpel); SM (LigaSure); TB (Thunder Beat)

\begin{tabular}{|c|c|c|c|c|}
\hline & EC & $\mathrm{HS}$ & LS & TB \\
\hline Drainage volume - median [range], $\mathrm{mL}$ & $640[30-720]$ & 600 [30-650] & $600[90-750]$ & 520 [60-670] \\
\hline Drainage removal - mean [range], days & $5,6[2-10]$ & $5,1[2-9]$ & $6[3-9]$ & $5,52[3-11]$ \\
\hline Hospital stay - median [range], days & $6[3-11]$ & $5,6[3-10]$ & $6,3[3-11]$ & $5,9[4-13]$ \\
\hline Seroma - n. (\%) & $14(64 \%)$ & $6(24 \%)$ & $11(44 \%)$ & $4(16 \%)$ \\
\hline Lymphedema - n. (\%) & $2(8 \%)$ & $2(8 \%)$ & $1(4 \%)$ & $0(0 \%)$ \\
\hline Wound infection - n. (\%) & $1(4 \%)$ & $0(0 \%)$ & $1(4 \%)$ & $1(4 \%)$ \\
\hline
\end{tabular}


Seroma Formation

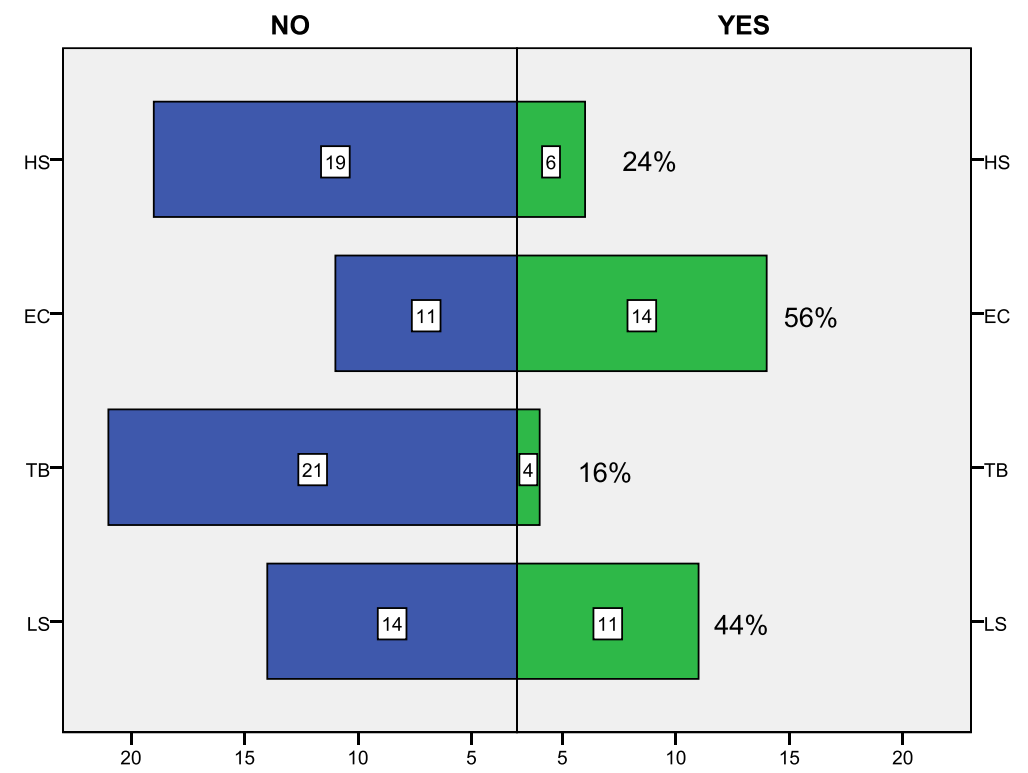

Fig. 2 Relative frequency percentage referred to upcoming seroma of individual instrument. LS (Ligasure); TB (Thunderbeat); EC (Electrocautery); HS (Harmonic Scalpel)

reduction of the thermal damage to the surrounding tissues, and subsequently of the inflammatory processes, among the main pathogenetic hypothesis of the common side effects of breast surgery, could led to a sharp improvement of postoperative outcomes.

To the best of our knowledge, this is the first comparative study on breast and axilla surgery involving and comparing all the three major advanced hemostasis devices vs EC. In our series HS and LS did not show any significant difference in terms of intra-operative blood loss (Fig. 2) and post-operative variables (drainage output, seroma formation) compared to other devices, confirming the conflicting outcomes present in Literature.

Otherwise, in the comparison between TB and EC, the Authors founded a statistically significant reduction for intra-operative blood loss and post-operative drainage output $(p<0,05)$, associated to a substantial reduction of seroma incidence $(16 \%$ for TB vs $64 \%$ for EC $p=0,004)$. These results could be due to a more effective closure of the vessels, given by the combination of ultrasonic and advanced bipolar energy, confirming the theory of lymphatic origin of seroma $[9,27]$. Moreover, the results presented by the Authors on safety and efficacy underlined that the new generation devices did not affect the number of lymphnodes harvested and the incidence of postoperative bleeding or neural injury.

Concerning TB's costs for breast surgery, a cost-benefit analysis is still matter of intense debate. Nevertheless, a review of 2014 by Shabbir et al. showed a lower cost for TB compared to HS and LS [16].
Our study presents some limitations, such as the limited number of patients involved and the retrospective nature, but the Authors tried to reduce these biases by selecting consecutives clinical cases following a chronological order. Moreover, should be considered that in case of radical mastectomy, breast and axillary cavities are interconnected, and therefore, the drain output is certainly higher compared to quadrantectomy alone. Nevertheless, the results observed could be a starting point to proceed with a prospective study on the use of advanced hemostasis devices for breast surgery.

\section{Conclusion}

In patients affected by breast cancer requiring ALND, the use of advanced hemostasis devices is highly desirable. Among the non-traditional tools, TB resulted to be superior in terms of reduction of intra-operative blood loss and post-operative drainage output, moreover associated to a substantial reduction of postoperative seroma incidence. LS and HS presented intraoperative and postoperative outcome essentially superimposable among them, even if LS was affected by a sharply high incidence of seroma formation. Further prospective randomized controlled studies are needed in order to evaluate the clear advantages of TB in breast cancer, considering also a detailed analysis of costs.

\section{Abbreviations}

ALN: Axillary Lymph Nodes; ALND: Axillary Lymph Nodes Dissection; EC: Elettrocautery; HS: Harmonic Scalpel; LS: Ligasure; Qu: Quadrantectomy; 
RM: Radical Mastectomy; SLNB: Sentinel Lymph Node Biopsy; TB: Thunderbeat

\section{Acknowledgements}

N/A

\section{Funding}

This article did not receive sponsorship for publication.

\section{Availability of data and materials}

The datasets used and/or analyzed during the current study are available from the VII Division of General Surgery, University of Campania "Luigi Vanvitelli", Via Pansini 5 80,131 Naples, on reasonable request.

\section{About this supplement}

This article has been published as part of BMC Surgery Volume 18 Supplement 1, 2018: Updates and New Technology in Endocrine Surgery. The full contents of the supplement are available online at https://bmcsurg.biomedcentral. com/articles/supplements/volume-18-supplement-1.

\section{Authors' contributions}

All authors contributed significantly to the present research and reviewed the entire manuscript. GC: Performed the surgery, participated substantially in conception, design and execution of the study and in the analysis and interpretation of the data; also participated substantially in the drafting and editing of the manuscript and in the statistical analysis. CIG: Participated substantially in conception, design and execution of the study and in the analysis and interpretation of the data; also participated substantially in the drafting and editing of the manuscript and in the statistical analysis. PR: Participated substantially in conception, design and execution of the study and in the analysis and interpretation of the data. OC: Participated substantially in conception, design and execution of the study and in the analysis and interpretation of the data. MC: Participated substantially in conception, design and execution of the study and in the analysis and interpretation of the data. RR: Participated substantially in conception, design and execution of the study and in the analysis and interpretation of the data. FM: Participated substantially in conception, design and execution of the study and in the analysis and interpretation of the data. CA: Participated substantially in conception, design and execution of the study and in the analysis and interpretation of the data. SA: Participated substantially in conception, design and execution of the study and in the analysis and interpretation of the data. PA: Participated substantially in conception, design and execution of the study and in the analysis and interpretation of the data. AN: Participated substantially in conception, design and execution of the study and in the analysis and interpretation of the data. CG: Performed the surgery, participated substantially in conception, design and execution of the study and in the analysis and interpretation of the data. All of the authors have read an approved the final manuscript.

\section{Author information}

Gambardella Claudio and Mauriello Claudio are PhD student in Medical, Clinical and Sperimental Sciences at Univerity of Campania "Luigi Vanvitelli" Naples, Italy.

\section{Ethics approval and consent to participate}

Not applicable, data retrospectively obtained by clinical records. In the University of Campania Luigi Vanvitelli Surgical Department, before surgery, the Authors submitted to all patients a written informed consent to eventually publish their clinical data. All patients gave their consent to publish.

\section{Consent for publication}

In the University of Campania Luigi Vanvitelli Surgical Department, before surgery, the Authors submitted to all patients a written informed consent to eventually publish their clinical data. All patients gave their consent to publish.

\section{Competing interests}

The authors declare that they have no competing interests.

\section{Publisher's Note}

Springer Nature remains neutral with regard to jurisdictional claims in published maps and institutional affiliations.

\section{Author details}

'Division of General and Oncologic Surgery - Department of Traslational Medical Sciences, University of Campania "Luigi Vanvitelli", Via Sergio Pansini 5, 80131 Naples, Italy. Endocrine Surgery Unit, University of Perugia, Piazza dell'Università, 06123 Perugia, Italy.

Received: 18 September 2018 Accepted: 5 December 2018 Published: 24 April 2019

\section{References}

1. Coviello V, Buzzoni C, Fusco M, Barchielli A, Cuccaro F, De Angelis R, Giacomin A, Luminari S, Randi G, Mangone L. AIRTUM working group. Survival of cancer patients in Italy. Epidemiol Prev. 2017;41(2 Suppl 1):1-244.

2. Kalager M, Zelen M, Langmark F, Adami HO. Effect of screening mammography on breast-cancer mortality in Norway. N Engl J Med. 2010; 363:1203-10.

3. Tardioli S, Ballesio L, Gigli S, Di Pastena F, D'Orazi V, Giraldi G, Monti M, Amabile MI, Pasta V. Wire-guided Localization in Non-palpable Breast Cancer: Results from Monocentric Experience. Anticancer Res. 2016;36(5): 2423-7.

4. National Comprehensive Cancer Network. (NCCN) NCCN Clinical Practice Guidelines in Oncology: Breast Cancer. Fort Washington PA: NCCN; 2015.

5. Gonzalez EA, Saltzstein EC, Riedner CS, Nelson BK. Seroma formation following breast cancer surgery. Breast J. 2003;9(5):385-8.

6. Tejler G, Aspegren K. Complications and hospital stay after surgery for breast cancer: a prospective study of 385 patients. Br J Surg. 1985;72(7): 542-4.

7. Hashemi E, Kaviani A, Najafi M, Ebrahimi M, Hooshmand H, Montazeri A. Seroma formation after surgery for breast cancer. World I Surg Oncol. 2004;2:44

8. Woodworth PA, McBoyle MF, Helmer SD, Beamer RL. Seroma formation after breast cancer surgery: incidence and predicting factors. Am Surg. 2000;66(5):444-50.

9. Srivastava V, Basu S, Shukla VK. Seroma formation after breast cancer surgery: what we have learned in the last two decades. J Breast Cancer. 2012;15(4):373-80

10. Watt-Boolsen S, Nielsen VB, Jensen J, Bak S. Postmastectomy seroma. A study of the nature and origin of seroma after mastectomy. Dan Med Bull. 1989;36:487-9.

11. Petrek JA, Senie R., Peters M, Rosen PP. Lymphedema in a cohort of breast carcinoma survivors 20 years after diagnosis. Cancer 2001; 15;92(6):1368-77.

12. Puttawibul P, Sangthong B, Maipang T, Sampao S, Uttamakul P, Apakupakul N. Mastectomy without drain at pectoral area: a randomized controlled trial. J Med Assoc Thail. 2003;86(4):325-31.

13. Nespoli L, Antolini L, Stucchi C, Nespoli A, Valsecchi MG, Gianotti L. Axillary lymphadenectomy for breast cancer. A randomized controlled trial comparing a bipolar vessel sealing system to the conventional technique. Breast. 2012;21(6):739-45.

14. Militello G, De Marco P, Falco N, Kabhull K, Mascolino A, Licari L, Tutino R, Cocorullo G, Gulotta $G$. Is it really useful the harmonic scalpel in axillary dissection for locally advanced breast cancer? A case series. G Chir. 2016; 37(6):262-5.

15. Yamamoto D, Yamada M, Okugawa H, Yonekura Y, Tanaka K. A comparison between electrocautery and scalpel plus scissor in breast conserving surgery. Oncol Rep. 2003;10(6):1729-32.

16. Shabbir A, Dargan DP. Advancement and benefit of energy sealing in minimally invasive surgery. Asian J Endosc Surg. 2014;7(2):95-101.

17. Heniford BT, Matthews BD, Sing RF, Backus C, Pratt B, Greene FL. Initial results with an electrothermal bipolar vessel sealer. Surg Endosc. 2001;15: 799-801.

18. Ceccanti S, Falconi I, Frediani S, Boscarelli A, Catani M, Cozzi DA. The THUNDERBEAT system for tissue dissection and vascular control in laparoscopic splenectomy. Minim Invasive Ther Allied Technol. 2017;26(4): 249-52.

19. Lyman GH, Somerfield MR, Bosserman LD, Perkins CL, Weaver DL, Giuliano AE. Sentinel lymph node biopsy for patients with early-stage breast Cancer: American Society of Clinical Oncology clinical practice guideline update. J Clin Oncol 2017; 10;35(5):561-564.

20. Veronesi U, Paganelli G, Galimberti V, Viale G, Zurrida S, Bedoni M, Costa A, De Cicco C, Geraghty JG, Luini A, Sacchini V, Veronesi P. Sentinel-node 
biopsy to avoid axillary dissection in breast cancer with clinically negative lymph nodes. Lancet. 1997;349:1864-7.

21. Follacchio GA, Monteleone F, Anibaldi P, De Vincentis G, lacobelli S, Merola R, D'Orazi V, Monti M, Pasta V. A modified sentinel node and occult lesion localization (SNOLL) technique in non-palpable breast cancer: a pilot study. J Exp Clin Cancer Res. 2015:6(34):113.

22. Maguire R, Brogi E. Sentinel lymph nodes for breast carcinoma: a paradigm shift. Arch Pathol Lab Med. 2016;140(8):791-8.

23. Amabile Ml, Monti M, Merola R, Frusone F, D'Orazi V, Pasta V. Nipple-sparing Mastectomy in Patients with Preoperative Diagnosis of Non-invasive Breast Carcinoma. A Single-center Experience. Anticancer Res. 2016;36(2):779-83.

24. Pogson CJ, Adwani A, Ebbs SR. Seroma following breast cancer surgery. Eur J Surg Oncol. 2003;29(9):711-7.

25. Boostrom SY, Throckmorton AD, Boughey JC, Holifield AC, ZakariaS HTL. Incidence of clinically significant seroma after breast and axillary surgery. J Am Coll Surg. 2009;208(1):148-50.

26. Kumar S, Lal B, Misra MC. Post-mastectomy seroma: a new look into the aetiology of an old problem. J R Coll Surg Edinb. 1995:40:292-4.

27. Sanjitha S, Gabriel R. Seroma formation after mastectomy: pathogenesis and prevention. Indian J Surg Oncol. 2010;1(4):328-33.

28. Oertli D, Laffer U, Haberthuer F, Kreuter U, Harder F. Perioperative and postoperative tranexamic acid reduces the local wound complication rate after surgery for breast cancer. Br J Surg. 1994;81:856-9.

29. Lumachi F, Basso SM, Bonamini M, Marino F, Marzano B, Milan E, Waclaw BU, Chiara GB. Incidence of arm lymphoedema following sentinel node biopsy, axillary sampling and axillary dissection in patients with breast cancer. In Vivo. 2009:23(6):1017-20.

30. Petrek J, Peters MM, Nori S, Knauer C, Kinne DW, Rogatko A. Axillary lymphadenectomy: a prospective, randomized trial of 13 factors infuencing drainage, including early or delayed arm mobilization. Arch Surg 1990; 125 : 378-382 8.

31. Archana A, Sureshkumar S, Vijayakumar C, Palanivel C. Comparing the Harmonic Scalpel with Electrocautery in Reducing Postoperative Flap Necrosis and Seroma Formation after Modified Radical Mastectomy in Carcinoma Breast Patients: A Double-Blind Prospective Randomized Control Trail. Cureus. 2018;10(4):e2476. https://doi.org/10.7759/cureus.2476.

32. Ebner F, Friedl TWP, de Gregorio A, Lato K, Bekes I, Janni W, de Gregorio N. Seroma in breast surgery: all the surgeons fault? Arch Gynecol Obstet. 2018; 298(5):951-59. https://doi.org/10.1007/s00404-018-4880-8.

33. Porter KA, O'Connor S, Rimm E, Lopez M. Electrocautery as a factor in seroma formation following mastectomy. Am J Surg. 1998;176:8-11.

34. Van Bemmel AJ, van de Velde CJ, Schmitz RF, Liefers GJ. Prevention of seroma formation after axillary dissection in breast cancer: a systematic review. Eur J Surg Oncologia. 2011;37(10):829-35 12.

35. Pogson CJ, Adwani A, Ebbs SR. Seroma following breast cancer surgery. Eur J Surg Oncol 2003: 29:711-717 13.

36. Agrawal A, Ayantunde AA, Cheung KL. Concepts of seroma formation and prevention in breast cancer surgery. ANZ J Surg. 2006:76:1088-95.

37. O'Hea BJ, Ho M, Petrek JA. External compression dressing versus standard dressing after axillary lymphadenectomy. Am J Surg. 1999;177:450-3.

38. Ouldamer L, Bonastre J, Brunet-Houdard S, Body G, Giraudeau B, Caille A. Dead space closure with quilting suture versus conventional closure with drainage for the prevention of seroma after mastectomy for breast cancer (QUISERMAS): protocol for a multicentre randomised controlled trial. BMJ Open. 2016;6(4):e009903.

39. Chintamani SV, Singh J, Bansal A, Saxena S. Half versus full vacuum suction drainage after modified radical mastectomy for breast cancer- a prospective randomized clinical trial. BMC Cancer. 2005;5:11.

40. Divino CM, Kuerer HM, Tartter PI. Drains prevent seromas following lumpectomy with axillary dissection. Breast J. 2000;6:31-3.

41. Ruggiero R, Procaccini E, Gili S, Cremone C, Parmeggiani D, Conzo G, Docimo L, Sparavigna L, Gubitosi A, Docimo G, Sanguinetti A, Avenia N. New trends on fibrin glue in seroma after axillary lymphadenectomy for breast cancer. G Chir. 2009;30(6-7):306-10

42. Docimo G, Limongelli P, Conzo G, Gili S, Bosco A, Rizzuto A, Amoroso V, Marsico S, Leone N, Esposito A, Vitiello C, Fei L, Parmeggiani D, Docimo L. Axillary lymphadenectomy for breast cancer in elderly patients and fibrin glue. BMC Surg. 2013;13(Suppl 2):S8.

43. Ruggiero R, Procaccini E, Piazza P, Docimo G, lovino F, Antoniol G, Irlandese E, Gili S, Lo Schiavo F. Effectiveness of fibrin glue in conjiuction with collagen patches to reduce seroma formation after axillary ymphadenectomy for breast cancer. Am J Surg. 2008;196(2):170-4

44. van Bastelaar J, van Roozendaal L, Granzier R, Beets G, Vissers Y. A systematic review of flap fixation techniques in reducing seroma formation and its sequelae after mastectomy. Breast Cancer Res Treat. 2018;167(2):409-16.

45. Pan XF, Huan JL, Qin XJ. Potential risk factors for the development of seroma following mastectomy with axillary dissection. Mol Clin Oncol. 2015;3(1):222-6.

46. lovino F, Auriemma PP, Ferraraccio F, Antoniol G, Barbarisi A. Preventing seroma formation after axillary dissection for breast cancer: a randomized clinical trial. Am J Surg. 2012;203(6):708-14.

47. Gong $Y, X u$ J, Shao J, Cheng $H$, Wu X, Zhao D, Xiong B. Prevention of seroma formation after mastectomy and axillary dissection by lymph vessel ligation and dead space closure: a randomized trial. Am J Surg. 2010;200:352-6

48. Herd-Smith A, Russo A, Muraca MG, Del Turco MR, Cardona G. Prognostic factors for lymphedema after primary treatment of breast carcinoma. Cancer. 2001:92:1783-7.

49. Ohlinger R, Gieron L, Rutkowski R, Kohlmann T, Zygmunt M, Unger J. The use of TissuGlu ${ }^{\oplus}$ surgical adhesive for mastectomy with or without lymphonodectomy. In Vivo. 2018;32(3):625-31.

50. Currie A, Chong K, Davies GL, Cummins RS. Ultrasonic dissection versus electrocautery in mastectomy for breast cancer-a meta-analysis. European journal of surgical oncology: the journal of the European Society of Surgical Oncology and the British association of. Surg Oncol. 2012;38:897-901.

51. Chavan RN, Chikkala B, Mondal P, Sarkar DK. Comparison Study Between Scalpel and Electrocautery, in Causation of Seroma After Modified Radical Mastectomy. Indian J Surg. 2017;79(5):423-6.

52. Lumachi F, Basso SM, Santeufemia DA, Bonamini M, Chiara GB. Ultrasonic dissection system technology in breast cancer: a case-control study in a large cohort of patients requiring axillary dissection. Breast Cancer Res Treat. 2013:142(2):399-404

53. Sanguinetti A, Docimo G, Ragusa M, Calzolari F, D'Ajello F, Ruggiero R, Parmeggiani D, Pezzolla A, Procaccini E, Avenia N. Ultrasound scissors versus electrocautery in axillary dissection: our experience. G Chir. 2010;31(4):151-3.

54. Hung SH, Chu D, Chen FM, Chen T, Chen RC. Evaluation of the harmonic scalpel in breast conserving and axillary staging surgery. J Chin Med Assoc. 2012;75(10):519-23.

55. Adwani A, Ebbs SR. Ultracision reduces acute blood loss but not seroma formation after mastectomy and axillary dissection: a pilot study. Int J Clin Pract. 2006:60(5):562-4.

56. Nawaz A, Waqar S, Khan A, Mansoor R, Butt UI, Ayyaz M. Harmonic Scalpe versus electrocautery in axillary dissection in carcinoma breast. J Coll Physicians Surg Pak. 2015;25(12):870-3.

57. Selvendran $S$, Cheluvappa $R$, Tr Ng VK, Yarrow S, Pang TC, Segara D, Soon P. Efficacy of harmonic focus scalpel in seroma prevention after axillary clearance. Int J Surg. 2016:30:116-20.

58. Manjunath S, Ramesh RS, K S, Goel V. Ultrasonic shears versus electrocautery in axillary dissection for breast cancer-a randomized controlled trial. Indian J Surg Oncol. 2014;5(2):95-8

59. Chang YW, Kim HS, Jung SP, Woo SU, Lee JB, Bae JW, Son GS. Comparison of skin-sparing mastectomy using LigaSure ${ }^{\mathrm{TM}}$ small jaw and electrocautery. World J Surg Oncol. 2017;15:129.

60. Manouras A, Markogiannakis H, Genetzakis M, Filippakis GM, Lagoudianakis EE, Kafiri G, Filis K, Zografos GC. Modified radical mastectomy with axillary dissection using the electrothermal bipolar vessel sealing system. Arch Surg. 2008;143(6):575-80.

61. Seki T, Hayashida T, Takahashi M, Jinno H, Kitagawa Y. A randomized controlled study comparing a vessel sealing system with the conventional technique in axillary lymph node dissection for primary breast cancer. Springerplus. 2016;5(1):1004.

62. Miyagi K, Rossi SH, Malata CM, Forouhi P. Novel use of LigaSure impact ${ }^{\text {TM }}$ electrosurgical bipolar vessel sealing system in skin-sparing mastectomy. J Plast Reconstr Aesthet Surg. 2015 Jun;68(6):e126-8.

63. Antonio M, Pietra T, Domenico LG, Massimo D, Ignazio R, Antonio N, Luig $C$. Does LigaSure ${ }^{\mathrm{TM}}$ reduce fluid drainage in axillary dissection? A randomized prospective clinical trial. Ecancermedicalscience. 2007;1:61.

64. Tukenmez M, Agcaoglu O, Aksakal N, Destek S, Cabioglu N, Barbaros U, Erbil Y, Bozbora A, Dinccag A, Ozmen V, Muslumanoglu M, Igci A. The use of 
Ligasure vessel sealing system in axillary dissection; effect on seroma formation. Chirurgia (Bucur). 2014;109(5):620-5.

65. Ramesh RS, Manjunath S, Shivakumar K, Philip R, Selvan S. Use of ultrasonic shears in patients with breast cancer undergoing axillary dissection-a pilot study. Indian J Surg Oncol. 2011;2(3):156-8.

66. Magri K, Bertrand V, Sautière JL, X. Pivot X, Riethmuller D, Maillet R, Marinkovic Z. Cost effectiveness of Ligasure precise versus surgical clips during axillary nodal dissection for breast cancer. J Gynecol Obstet Biol Reprod (Paris) 2006 Jun;35(4):341-347.

67. Van Slycke S, Gillardin JP, Van Den Heede K, Minguet J, Vermeersch H, Brusselaers N. Comparison of the harmonic focus and the thunderbeat for open thyroidectomy. Langenbeck's Arch Surg. 2016 Sep;401(6):851-9.

Ready to submit your research? Choose BMC and benefit from:

- fast, convenient online submission

- thorough peer review by experienced researchers in your field

- rapid publication on acceptance

- support for research data, including large and complex data types

- gold Open Access which fosters wider collaboration and increased citations

- maximum visibility for your research: over $100 \mathrm{M}$ website views per year

At $\mathrm{BMC}$, research is always in progress.

Learn more biomedcentral.com/submissions 